\title{
Autonomy and the patient's right 'not to know' in clinical whole-genomic sequencing
}

\section{European Journal of Human Genetics (2014) 22, 6; doi:10.1038/ejhg.2013.94; published online 15 May 2013}

In their recent publication on whole-genomic sequencing (WGS), Ayuso et $a l^{1}$ identify ethical challenges around the disclosure of 'incidental findings' (IF) and propose recommendations for informed consent (IC) in a clinical setting. They note that WGS could become clinically routine as technologies develop and time and cost of testing decreases. Based on a comprehensive review and analysis of relevant literatures, they propose an ethical return of clinical IF. The authors suggest that at a minimum, the IC form for WGS for diagnostic purposes should include pre-test counseling and general information common to all genetic tests as well as additional content specific to WGS regarding IF (p1). ${ }^{1}$ Their proposed recommendations draw on Berg's ${ }^{2}$ category-based binning framework model of disclosure.

Ayuso et $\mathrm{al}^{1}$ provide helpful recommendations on both the process and content of IC in clinical WGS. Although we agree with the authors regarding the ethical challenges in clinical WGS, we disagree with one aspect of their recommendations: '...it is suggested that... clinically manageable disorders affecting the patient... must always be disclosed to the patient... on the other hand, the possible disclosure of other types of information.... should be discussed and agreed upon in advance with the patient during the informed consent process ${ }^{1}(\mathrm{p} 4)$. In our view, the first part of this statement is paternalistic, in that the clinician denies the patient the choice of 'not to know' and is predicated upon the 'physician as gatekeeper' model as opposed to a model of 'patient as partner' or 'patient as gatekeeper' of his or her own genomic information. The authors' stance appears counter to the current shift in patient-doctor relationships and the move toward greater patient autonomy, shared decision-making and empowerment in healthcare. It is also inconsistent with the European Convention on Human Rights and Biomedicine $e^{3}$ which states, 'Everyone is entitled to know any information collected about his or her health. However, the wishes of individuals not to be so informed shall be observed (p 436).

Honoring a patient's choice 'not to know' respects an individual's autonomy. ${ }^{4}$ However, taking the position that particular types of WGS information 'must always be disclosed' with no prior discussion, significantly undermines patient autonomy. There is some evidence in support of this. Participants in our focus group study, which explored lay and patient attitudes about WGS IF clinical disclosure, strongly supported the right to say no to disclosure..$^{5}$ Following Andorno ${ }^{3}$ we maintain that the right not to know must be offered but cannot be presumed, and must be 'activated' by a person's explicit choice. Also, it is not an absolute right; it may be restricted when disclosure relates to serious harm to third persons (p 435). ${ }^{3}$ Exercising this right 'not to know' should be an informed choice. The patient and doctor need to discuss the risks and implications of both knowing the results and not knowing them including the reliability of the information.

Individuals may have valid reasons for not knowing results. The 'objective' clinical utility of knowledge may have very different meaning 'subjectively' for patients in terms of its relevance and manageability for them; all things considered, they simply may make an informed choice not to have the information disclosed to them. The impact that all genetic information has on the individual, including psychological, social and financial consequences or harms, needs to be recognized by clinicians at all stages of disclosure. For instance, discrimination by insurance companies and employers or societal stigma may be a real threat. Other ethical issues may arise; the results may negatively impact autonomy in a broad sense of the word, that is impinge on a person's self-determination, autonomous lifestyle and future life plans. ${ }^{6}$ Crucially too, regardless of any potential consequences or negative effects that might derive from test results, the right not to know is an essential requirement for a person to decide freely whether or not to undergo WGS (p 147). ${ }^{6}$

Rather than assume disclosure of selective results with no discussion, it is important to understand why some people choose not to know, and to understand what that knowledge might mean in their life/personal contexts, beyond the clinic. As Andorno ${ }^{3}$ has noted, autonomy understood broadly, offers a theoretical basis for a right not to know one's genetic status. ${ }^{3}$ We agree with the authors that more dialogue is needed around these issues and our comments are intended to contribute to this debate as new ethical challenges emerge around IF and WGS clinical disclosure.

\section{CONFLICT OF INTEREST}

The authors declare no conflict of interest.

Anne Townsend ${ }^{\star, 1}$, Francois Rousseau ${ }^{2}$, Jan Friedman ${ }^{3}$ Shelin Adam ${ }^{3}$, Zoe Lohn ${ }^{3}$ and Patricia Birch ${ }^{3}$

${ }^{1}$ The W. Maurice Young Centre for Applied Ethics, University of British Columbia, Vancouver, $B C$, Canada; ${ }_{2}^{2}$ Medical Biology, Université Laval, Montreal, $P Q$, Canada;

${ }^{3}$ Medical Genetics, University of British Columbia,

Vancouver, BC, Canada E-mail: atownsen@exchange.ubc.ca

1 Ayuso C, Millan JM, Mancheno M, Dal-Re R: Informed consent for whole-genome sequencing studies in the clinical setting. Proposed recommendations on essential content and process. Eur J Hum Genet 2013; 21: 1054-1059.

2 Berg JS, Khoury MJ, Evans JP: Deploying whole genome sequencing in clinical practice and public health: meeting the challenge one bin at a time. Genet Med 2011; 13: 499-504.

3 Andorno R: The right not to know: an autonomy based approach. J Med Ethics 2004 30: 435-440.

4 Chadwick R: The philosophy of the right to know and the right not to know; in Chadwick R Levitt M, Shickle D (eds) The Right to Know and the Right Not to Know. London. Aldershot: Ashgate Publishing Company, 1997; pp 13-22.

5 Townsend A, Adam S, Birch P, Friedman J, Lohn Z, Rousseau F: I want to know what's in Pandora's box: comparing stakeholder perspectives on incidental findings in clinical whole genomic sequencing. Am J Med Genet Part A 2012; 158A 2519-2525.

6 Hildt E: Predictive Genetic Testing, Autonomy and Responsibility for Future Health Med Studies 2009; 1: 143-153. 